\title{
Weather Prediction using Machine Learning and IOT
}

\author{
Gopinath N, Vinodh S, Prashanth P, Jayasuriya A, Deasione S
}

\begin{abstract}
This project proposes a method for forecasting weather conditions and predicting rainfall by means of machine learning. Here, there are two set ups: one, to measure the weather parameters like temperature, humidity using sensors along with Arduino and another set up, to display the current values(status) and predicted rainfall based on the trained machine learning data sets. The weather forecasting and prediction is done based on the older datasets collected and compared with the current values. The user need not have a backup of huge data to predict the rainfall. Instead a machine learning algorithm can suffice the same. The temperature, humidity sensor modules are used to measure weather parameters and interfaced to an Arduino controller. The proposed setup will compare the forecast value with real-time data, and the predict rainfall based on the dataset fed to the machine learning algorithm.
\end{abstract}

Keywords: Arduino, Humidity sensor, Machine Learning, Temperature.

\section{INTRODUCTION}

Most of the advanced Weather Forecasting Systems in existence today, require big and expensive changes of infrastructure. This means that it often is not feasible to install a new monitoring system in an existing weather station. This Machine learning based Weather Forecasting System is a monitoring system that is supposed to be implemented in existing weather stations, without any changes in the existing infrastructure. This system lets the user or an engineer to monitor and predict the rainfall from this hardware setup without any additional installations. In the microcontroller, the user can program actions what should happen with electrical devices in the network depending on the sensors sensing surrounding environment.

There will be a receiving section and input section separately, so they can exchange information with the Personal Computer. People can control power supply of

Revised Manuscript Received on April 25, 2020.

* Correspondence Author

Gopinath N*, Assistant Professor, Dept. of CSE, Sri Manakula Vinayagar Engineering College, Puducherry, India. Email: gopinathit14@gmail.com

Vinodh S, Student, Dept. of CSE, Sri Manakula Vinayagar Engineering College, Puducherry, India. Email: s.vinodh1002@gmail.com

Prashanth P, Student, Dept. of CSE, Sri Manakula Vinayagar Engineering College, Puducherry, India. Email: prashshock@gmail.com

Jayasuriya A, Student, Dept. of CSE, Sri Manakula Vinayagar Engineering College, Puducherry, India. Email: jayasuriyaarumugam@gmail.com

Deasione S, Student, Dept. of CSE, Sri Manakula Vinayagar Engineering College, Puducherry, India. Email: littered.inbox@gmail.com

(C) The Authors. Published by Blue Eyes Intelligence Engineering and Sciences Publication (BEIESP). This is an open access article under the CC BY-NC-ND license (http://creativecommons.org/licenses/by-nc-nd/4.0/) electrical devices in order to create an interactive environment to facilitate the control without changing any available device. People can enjoy the high technology and simplicity modern life style.

Each device will be with standard setup and while adding it into network; it can be given a task to do. The machine learning technology is made use of to wade away the problem of having historical backup thereby making the whole system to be user friendly.

In this project, there is a separate set up for measuring temperature and humidity level and one set up for storing and displaying their respective input values in a computer, and predict the rainfall based on the trained datasets varying on the needed functionality. Various different sensors could be attached to the boxes. The sensors are used as triggers for actions, that user can set up in the controller program.

The project is aimed at developing and testing the use of Machine learning to predict and take a decision in providing the information about future weather conditions in a weather station. The microcontroller would then control any device based on the information given to it from the sensor module. The solution will need to be easy to use, simple, secure, and robust. To achieve this testing will need to be carried out to create a useful system.

\section{LITERATURE SURVEY}

1. M.K. Nallakaruppan and U. Senthil Kumaran proposed this concept of predicting weather forecasting. Here weather prediction is done by using linear regression. Linear regression is most familiar one, it is used to depict the information and illustrate connection between the dependent and independent factor. It finds best fit through graph points. The line may be straight or curved based on data. They can also be quadratic or polynomial. Decision tree and time series analysis is used here.

It uses Raspberry $\mathrm{Pi}$, consisting 4 USB ports and an ethernet port. It consists of many sensors, and a power supply also given to this, a HDMI port is available which gives connection interfaceable screen. A Micro SD is attached to Raspberry OS. Here coding used is python, data stored in MYSQL server. The moto was to use expensive components and attain maximum accuracy. Accuracy here done by using machine learning concepts. Here ARIMA used instead of Decision tree to dynamic behavior capturing, hence results in compact and natural internal representation of temporal information. 2. S.Akter Nishe and Tahmina Aziz reported that a system to gather data for accurate weather predictions can be developed with Arduino and mobile application. Here, a basic android application is used in the mobile phone which various users can feed weather data for future predictions.

Published By:

Blue Eyes Intelligence Engineering \& Sciences Publication (C) Copyright: All rights reserved. 
This proposal presents the design and implementation of an efficient but flexible and accurate weather prediction system. The design is based on a standalone Arduino board and the sensors for temperature, humidity along with GPS and Bluetooth modules are used. The communication between the mobile phone and Arduino board is wireless. This system is designed to mainly act as a source of weather data. The data collected is quantitative and continuous which is analyzed to show perfect correlation for accurate prediction.

Android application is being used by vast number of users and the data sent by them is compared with a standard weather data provider and the compared values fed to the database. The full functionality of the weather prediction system was tested and the wireless communication between mobile phone and Arduino was found to be limited only within Bluetooth range.

3. Nasimul Hassan suggested the idea of weather data analysis and prediction using Machine learning. This proposal put forward the weather data analysis and classifies the predicted rainfall based on various machine learning algorithms. Their findings suggest that their weather prediction classification comes with minimal error and outline relevant weather features. The proposal includes new age machine learning algorithms to enable easy predictions.

The developed system tries to achieve maximum accuracy in predicting the weather trained based on decision trees algorithm. The usage of machine learning algorithms eliminates the dependencies of huge backup data thereby predicting the weather based on the current sensor recordings.

4. Karthik Krishnamurthi and team proposed the idea of presenting the weather monitoring system based on Arduino board. They presented an automated system to monitor the weather conditions. The old data present in the database is taken into consideration for comparing and forecasting weather without human error. Their architecture includes temperature and humidity sensors coupled to Arduino along with Light dependent resistors. The old values are fetched from a personal computer and values are compared in Arduino based on the logic written. The output values are presented in form of LCD display.

The system proposed does not include the any new machine learning for weather data comparison. This becomes a shortfall for the forecasting model which sidelines the accuracy of prediction achieved using machine learning algorithms.

5. Amber Katyal and team proposed a model of wireless Arduino based weather station. Their model is helpful in critical scientific applications and simulation purposes. The main purpose of this project is to provide an efficient weather monitoring with the use of low-cost popular devices and instruments.

The working setup takes readings from various sensors and feed to the Arduino controller using Wi-Fi technology. The raindrop sensor modules are used in the proposed model for identifying probability of rain in nearby areas. All the collected data from the hardware setup is sent to the Cloud for storage purposes. This data available in the Cloud will be helpful in future for historical references.

6. Mark Holmstrom and team explored the idea of using Machine learning in the field of weather forecasting. The team potentially competed to make a model that will challenge the forecasting done by professional weather forecasting services. The sole aim was to bring accuracy in the prediction through the usage of machine learning algorithms.

The machine learning algorithm used was functional regression with a variation and linear regression. The historical data from public institutions was used for training the datasets and implement the predictions with apt accuracy. Both the algorithms proved to outperform the predictions provided by the professional agencies.

The performance of the models decreased their discrepancies with additional datasets and high computation time and thereby leaving this part of issue for future work.

\section{PROPOSED SYSTEM}

This project is used to measure the weather parameters in real time and predict the rainfall based on these values. Here through the sensor setup will interact with the microcontroller section which is controlling the end-use display and storage set up installed in weather forecasting station. The measured values are written to a file and these values are fed to the trained machine learning algorithm to predict the accuracy of rainfall.

The controller section is basically a microcontroller which is burnt with a program and will execute the operations according to it. According to the programming in the microcontroller, a command will be given to the sensor module to read the temperature humidity values continuously. The sensor sends the weather parameter values based on the relevant command through serial port to the microcontroller over serial interface. The microcontroller is a TTL family device and to interface it with sensor module and Personal computer an interface is needed.

The Universal serial bus cable helps in connecting microcontroller to Personal and provides serial communication between the two. The controller on receiving the command performs the operations and control the operation of the system connected to it. Based on this command, the controller sends the control signal to store and display the read values. Same way, the temperature and humidity ranges are measured based on the command received in the controller and the data is sent back to the forecasting system.

\section{COMPONENTS USED}

\section{A. Hardware Components}

\begin{tabular}{|c|c|c|}
\hline S.No. & $\begin{array}{c}\text { Name Of } \\
\text { Components }\end{array}$ & Quantity \\
\hline 1. & Arduino Uno kit & 1 \\
\hline 2. & DHT11 sensor & 1 \\
\hline 3. & LCD module & 1 \\
\hline 4. & Personal Computer & 1 \\
\hline
\end{tabular}

List of Hardware Components

Published By:

Blue Eyes Intelligence Engineering 


\begin{tabular}{|c|c|}
\hline DETAILS & SPECIFICATIONS \\
\hline Operating Voltage & $5 \mathrm{~V}$ \\
\hline Input Voltage & $7-20 \mathrm{~V}$ \\
\hline Digital I/O Pins & 14 \\
\hline Analog Input Pins & 6 \\
\hline Flash Memory & $32 \mathrm{~Kb}$ \\
\hline SRAM & $2 \mathrm{~Kb}$ \\
\hline EEPROM & $1 \mathrm{~Kb}$ \\
\hline Clock speed & $16 \mathrm{MHz}$ \\
\hline Specfications
\end{tabular}

\begin{tabular}{|c|c|}
\hline \multicolumn{1}{|c|}{ Specifications of Arduino Uno Board } \\
\hline DETAILS & SPECIFICATIONS \\
\hline Operating Voltage & $3.5 \mathrm{~V}-5 \mathrm{~V}$ \\
\hline Operating Current & $0.3 \mathrm{~mA}$ \\
\hline Output & Serial data \\
\hline $\begin{array}{c}\text { Temperature } \\
\text { Range }\end{array}$ & $0^{\circ} \mathrm{C}$ to $50^{\circ} \mathrm{C}$ \\
\hline $\begin{array}{c}\text { Humidity Range } \\
\text { Accuracy }\end{array}$ & $20 \%$ to $90 \%$ \\
\hline & $\pm 1^{\circ} \mathrm{C}$ and $\pm 1 \%$ \\
\hline
\end{tabular}

Specifications of DHT11

\section{B. Software}

In order to use Weather Forecasting system, several types of computer software is needed.

The software's are:
1. Arduino Compiler
2. PLX-DAX
3. Anaconda
4. Jupyter Notebook
5. Google Colab

\section{WORKING PRINCIPLE}

The working of the project "Weather forecasting system using Machine Learning" is described in the following sections.

Below is the detailed block diagram to explain the complete process of weather forecasting and prediction done with the help of artificial intelligence:

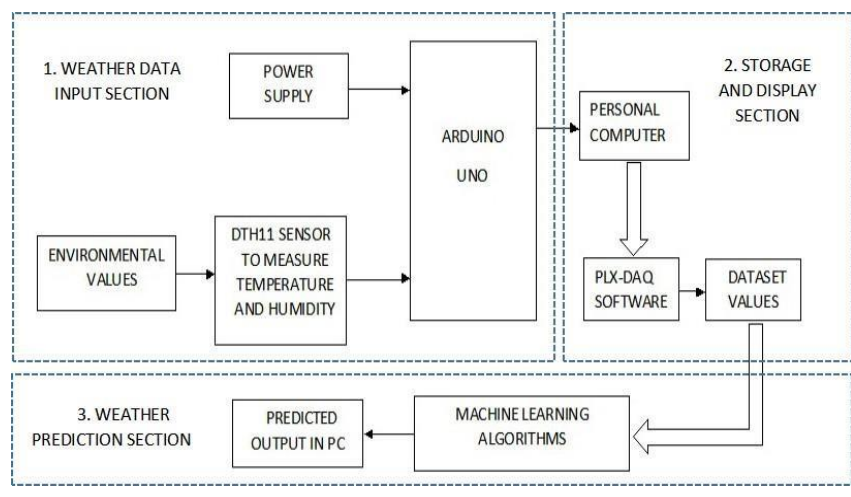

\section{A. Weather Data Input section}

In this section, a combined sensor to measure both temperature and humidity is used. The sensor works well to send the real time data continuously to the interfaced microcontroller. The controller is powered with a voltage supply after rectification done in a DC adapter. The function of this section is to collect the readings of the weather data. The measured values are ready for further processing based on the requirement.

\section{B. Storage and Display Section}

In this section, the output is then given to the Personal computer and then displayed in an Excel file. This is done by means of specific software to interface the Arduino output measured values to excel file. The final sheet of excel will be the dataset file available for the machine learning prediction.

\section{Weather Prediction Section}

This section includes the setup for the dataset being given as input to machine learning models to accurately predict the rainfall based on various algorithms. The algorithms will make the prediction based on various approaches and different sets of data. The predicted percentage value is displayed on the Personal computer and can be compared with previous historical weather inputs.

\section{FLOWCHART FOR HARDWARE SYSTEM}

In the hardware system, a flowchart is very essential to blindly understand how the communication process is getting started. So, this representation will help anyone and easily understand the process going on. A flow chart is drawn describing the way the communication gets started in the system. Here, first the all the devices are initialized. Then the availability of the sensor module is checked. If the sensor is available to read the input data, then the corresponding received Arduino command is checked. If it is not available, then further operations will not be performed until a module is ready to read.In the received command, the instructions are written for a specific operation. In the project, the Arduino will take care of the process of initiating the input read process and continue the forecasting and provide data for storage and prediction. When the corresponding actions are performed, the value of count is incremented. Based on the value of count, the respective actions are done and the values are checked. The below figure shows the complete flow chart which is implemented for the Weather forecasting and prediction using Machine Learning.

The flow chart for hardware system is shown below:

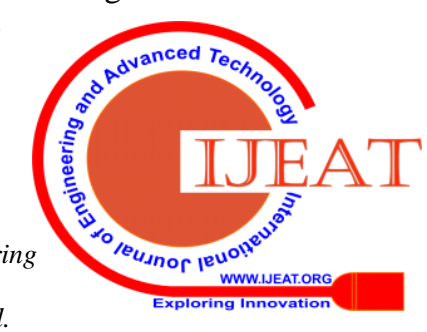




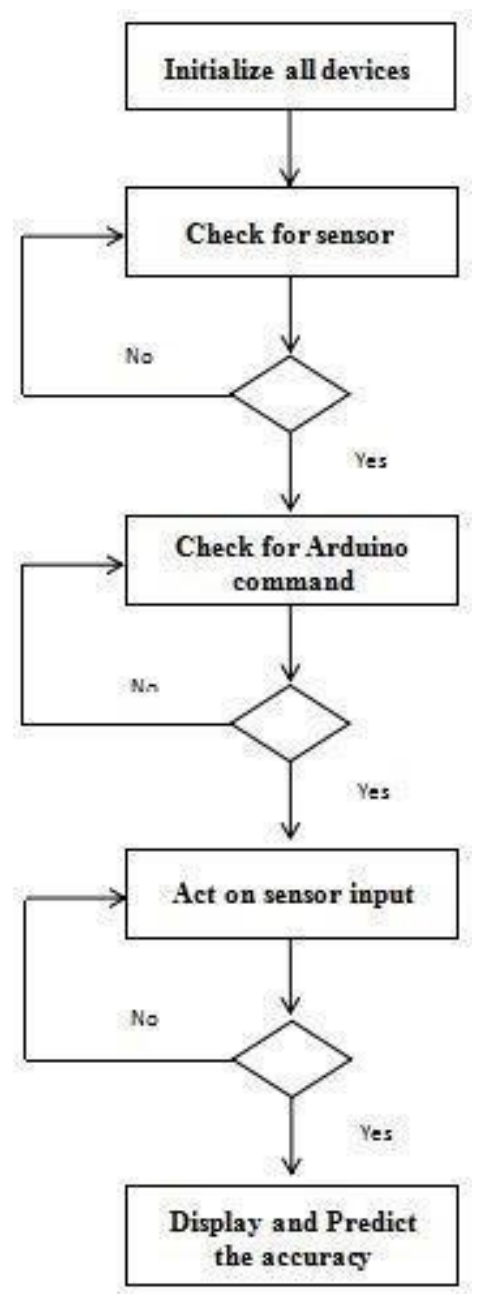

Fig. Flowchart for Hardware System

\section{RESULT}

The temperature data is feed as an input into the model. The data has been trained using Supervised Learning method in which different algorithms have been used such as K-Nearest Neighbors(KNN),Decision Tree Classifier(DT), Logistic Regression(LR), Support Vector Machine(SVM) and Random Forest Classifier(RFC).The trained model gets the input process it based on the algorithm and produces the output. Since it is a machine learning model so the output will be in terms of accuracy.

The graph shows the result of the different algorithm model in terms of accuracy. The X-axis indicated the model used and Y-axis indicated the accuracy of the model using train and test data set.

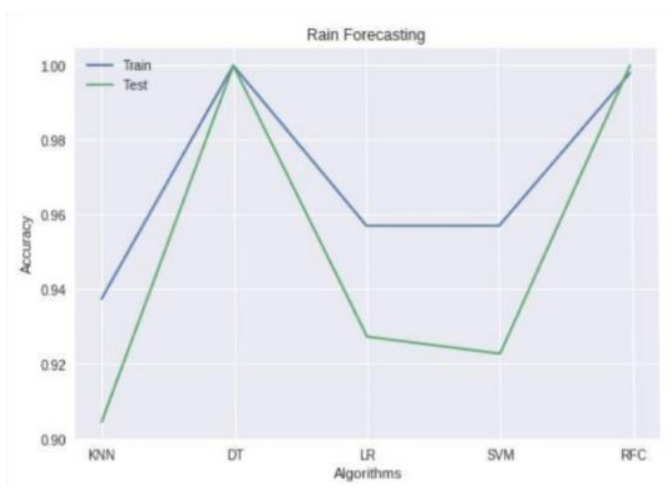

\section{CONCLUSION}

The conclusion is drawn that a very reliable, efficient and less cost product has been developed which can make life more comfortable and securable. This project does not require any hard installations and can be easily installed in old installations. So, it is easily compatible with old systems. Since the project is prediction based and thus doesn't require any extra cost of installing software.

Our project will prove to be efficient for many weather monitoring stations, as it will help them in having an alternative solution when there is any absence of the high cost weather monitoring setup. The rainfall prediction is done with the use of machine learning in minimal costs. The complete weather forecasting setup is flexible enough to be installed anywhere and make weather predictions without much historical experience.

\section{REFERENCE}

1. S.Akter Nishe and Tahmina Aziz "Micro-level Meterorological Data Sourcing for Accurate Weather Prediction" in IEEE Region 10 Humanitarian Technology Conference 2017.

2. Nasimul Hassan "Automated Weather Event Analysis with Machine Learning," in IEEE Region 10 Humanitarian Technology Conference 2017.

3. Karthik Krishnamurthi," Arduino Based Weather Monitoring System" in International Journal of Engineering Research and General Science Volume 3, Issue 2, March- April,2015.

4. Amber Katyal," Wireless Arduino Based Weather Station" in International Journal of Advanced Research in Computer and Communication Engineering Volume 5, Issue 4, March-April,2016.

5. Qing Yi Feng1, RuggeroVasile,Marc Segond4, AviGozolchiani, Yang Wang, Markus Abel, ShilomoHavlin, Armin Bunde, and Henk A. Dijkstra1 " ClimateLearn: A machine-learning approach for climate prediction using network measures,", Germany, 2016.

6. Siddharth S. Bhatkande1, Roopa G. Hubballi2 "Weather Prediction Based on Decision Tree Algorithm Using Data Mining Techniques", Belgaum India: International Journal of Advanced Research in Computer and Communication Engineering, 2016.

7. Aditi Kansal1, Yashwant Singh2, Nagesh Kumar3, Vandana Mohindru4" Detection of Forest Fires using Machine Learning Technique: A Perspective" 2015 Third International Conference on Image Infonnation Processing 978-1-5090-0148- 4/15/\$31.00@ 2015 IEEE

8. Muthulakshmi A, ME (SE), Dr.S.BaghavathiPriya " A survey on weather forecasting to predict rainfall using big data analytics", Chennai.: IJISET , 2015.

9. George E. Sakr, Imad H. Elhajj, George Mitri and Uchechukwu C. Wejinya" Artificial Intelligence for Forest Fire Prediction" 2010 IEEE/ASME International Conference on Advanced Intelligent Mechatronics Montréal, Canada, July 6-9, 2010.

10. Aditya Grover, AshishKapoor, Eric Horvitz (n.d.) “A Deep Hybrid Model for Weather Forecasting”, : Microsoft Research, Redmond.

11. John K. Williams and D. A. Ahijevych, C. J. Kessinger, T. R. Saxen, M. Steiner and S. Dettling National Center for Atmospheric Research, Boulder, Colorado (n.d.) "A Machine Learning Approach to finding weather regimes and skillful predictor combinations for short-term storm forecasting", Colorado.

12. Kwang Ye Lee, Jae Weon Choi, "Remote- Controlled Home Automation System via Bluetooth Home Network", SICE Annual Conference, Japan.

13. Deshmukh A. D. \&Shinde U. B. 2016, August. A low-cost environment monitoring system using raspberry $\mathrm{Pi}$ and arduino with Zigbee. In: Inventive Computation Technologies (ICICT), International Conference on. 3: 1-6. IEEE.

14. Jindarat S. \&Wuttidittachotti P. 2015, April. Smart farm monitoring using Raspberry Pi and Arduino.In: Computer. Communications, and Control Technology (I4CT), 2015 International Conference on . IEEE. pp. 284-288.
Published By:

Blue Eyes Intelligence Engineering \& Sciences Publication (C) Copyright: All rights reserved. 
15. Wang Y. \& Chi Z. 2016, July. System of Wireless Temperature and Humidity Monitoring Based on Arduino Uno Platform. In: Instrumentation \& Measurement, Computer, Communication and Control (IMCCC), 2016 Sixth International Conference on. IEEE. pp. 770-773.

16. Saini H., Thakur A., Ahuja S., Sabharwal N. \& Kumar N. 2016, February. Arduino based automatic wireless weather station with remote graphical application and alerts. In: Signal Processing and Integrated Networks (SPIN), 2016 3rd International Conference on. IEEE. pp. 605- 609.

17. Kumar N. P. \&Jatoth R. K. 2015 May. Development of cloud based light intensity monitoring system using raspberry Pi. In: Industrial Instrumentation and Control (ICIC), 2015 International Conference on.IEEE. pp. 1356- 1361.

18. Folea S. C. \&Mois G. 2015. A low-power wireless sensor for online ambient monitoring. IEEE Sensors Journal. 15(2): 742-749.

19. Sandeep V., Gopal K. L., Naveen S., Amudhan A

\& Kumar L. S. 2015, August. Globally accessible machine automation using Raspberry pi based on Internet of Things. In: Advances in Computing, Communications and Informatics (ICACCI), 2015 International Conference on. IEEE. pp. 1144-1147.

20. Princy S. E. \& Nigel K. G. J. 2015, November. Implementation of cloud server for real time data storage using Raspberry Pi. In: Green Engineering and Technologies (IC-GET), 2015 Online International Conference on . IEEE.

\section{AUTHORS PROFILE}

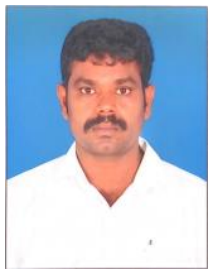

Mr. N. Gopinath is pursuing Ph.D under Sathyabama Institute of Science and Technology (Deemed to be University) in the field of Quantum Cryptography at present. He is working as Assistant Professor in the Department of Computer Science and Engineering at Sri Manakula Vinayagar Engineering College, Puducherry affiliated to Pondicherry University, Puducherry, India. He completed his Bachelor of Technology in Computer Science at Jeppiaar Maamallan Engineering College affiliated to Anna University and his Master of Technology in Computer Science at Adhiparasakthi Engineering College affiliated to Anna University.

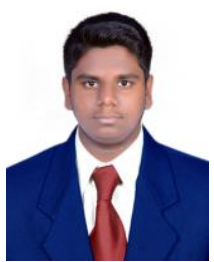

Vinodh $\mathbf{S}$ is pursuing his B.Tech degree in the stream of Computer Science and Engineering at Sri Manukula Vinayagar Engineering College, Puducherry affiliated to Pondicherry University, Puducherry, India. He has over all CGP of 7.9 and has a good knowledge in programing. He has completed his schooling at Vivekanandha Higher Secondary School, Puducherry, India with good academic performance. He wishes to work as an IT employee in the field of developing technologies in a reputed company so he is keen on developing his knowledge in digital technologies. He had participated and achieved in competitions conducted by IT company and Colleges.

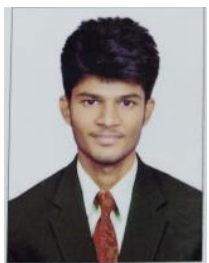

Prashanth $\mathbf{P}$ is pursuing Bachelor of Technology in the stream of Computer Science and Engineering at Sri Manakula Vinayagar Engineering College, Puducherry affiliated to Pondicherry University, Puducherry, India. His research interests include in the field of Android Application Development, IOT and Machine Learning.

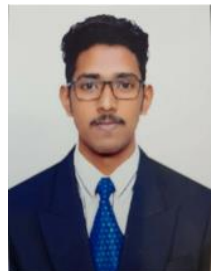

Jayasuriya A is a student of Sri Manakula Vinayaga Engineering College in which he pursuing Bachelor of technology in computer science and engineering. $\mathrm{He}$ has overall CGPA of 7.7 and has rich knowledge in computer science He has completed his schooling in panruti. He keeps on working to build his skills and have interest in networks. He acquired CCNA certification.

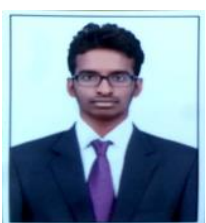

Deasione S is a student of Sri Manakula Vinayagar Engineering College in which he is pursuing his Bachelors of Technology in Computer Science and Engineering. He has an overall CGPA of 7.2 and has abundant knowledge on computer technologies. Deasione has been relentlessly working to build his skills and achieve his goals, this helps him fit for the

role of OSCP.

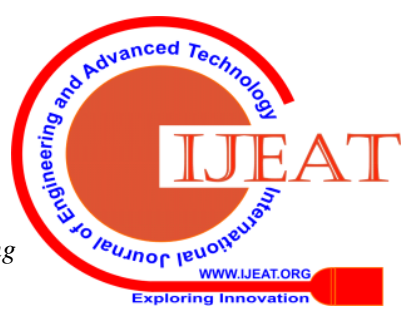

